\title{
SUSTAINING CULTURAL IDENTITY THROUGH ARABIC CALLIGRAPHY: A CRITICAL READING OF NASSER AL-SALEM'S ARTWORKS
}

\author{
LINA M. KATTAN* \\ University of Jeddah, Saudi Arabia
}

\begin{abstract}
Arabic calligraphy has always been the most prominent characteristic of Islamic art. Arab/Muslim artists - even non-Arabic speakers - appreciate Arabic calligraphy due to its correlation with the language of the Quran. Due to the commonly known prohibition of figuration, especially among classical Muslim scholars, many Arab/Muslim artists found an escape in the Arabic alphabet to avoid such a grey area. Either used as words or as sentences, Arabic inscription became the dominant pattern of traditional Islamic art. The inclusion of Arabic letters within the artistic composition has changed over the years, namely in style. Since the 1980s, the Arabic letter became the core element of contemporary Saudi art. In this paper, I argue that contemporary Saudi artists, such as in the case of Nasser al-Salem, rely on Arabic calligraphy to assert their Islamic identity and cultural heritage. This paper sheds light on one famous contemporary Saudi artist who chose the Arabic letter as his primary approach. While it may seem that al-Salem's contemporary works are similar to traditional Islamic arts, they tremendously differ in concept, medium, and style. This study focuses only on three of his well-known calligraphic works. Generally, what characterizes contemporary Saudi art is the high-level of conceptuality and the noticeable influence of Western art techniques. al-Salem has always been interested in the conceptuality of the Arabic alphabet and its compositional configuration; therefore, his reliance on Arabic script continues to affirm his Saudi cultural heritage and Islamic Identity. While preserving the sacredness and prominence of Arabic calligraphy, the Arabic alphabet/letter in al-Salem's contemporary art became an autonomous form that is highly charged with symbolism.

Keywords: calligraphy, alphabet, Saudi art, contemporary Islamic art, Nasser al-Salem, cultural heritage, identity, abstraction, non-objective, conceptuality.
\end{abstract}

\section{INTRODUCTION}

Calligraphy involves the art of producing decorative handwriting through the use of a brush or a pen, and it illustrates that writing can be a form of visual art that explores human invention, prowess, and ingenuity. Calligraphy is a popular art form in varied cultures; however, the practice and purpose differ from one culture to another. For example, Chinese calligraphy expresses personal empowerment, while Arabic calligraphy is highly religious and represents a direct link to the spiritual world [1]. In the past, Arabic calligraphy had various connotations due to its relation to the sacred scriptures of the Quran and traditional Arabic poetry, all of which inspired various artists and ultimately became the quintessential Islamic art form.

Conventionally, Islamic Arabic calligraphy can be witnessed in parchment or papyrus manuscripts. Moreover, traditional artists used materials other than paper such as ceramic, wood, silk, enameled glass, silver, and gold coins. It was the duty of a skilled penman (Khattat) to design and inscribe the Arabic-inspired artworks. This skilled penman would use the quill (Qalam), which is a traditional pen made from dried bamboo or reed [2]. The color chosen varied according to the intensity of the words in order to establish dynamism. In other cases, a metallic-tip pen would be used. The right to left reading style and hanging style is

*ORCID: https://orcid.org/0000-0003-4963-6061 
often used as a security feature to the manuscript. In both the decorated frames and background patterns, the rules of proportionality were strict, and configuration and punctuation were emphasized.

The concept of beauty differs through time and place. In Western art, the notion of writing is influenced by Ancient Greek art in which they had a modular concept based on alphabets. In Arabic calligraphy on the other hand, proportional thinking was introduced by Ali ibn Muqla al-Shirazi (885-940 CE) - an Abbasid Vizier - via rhomboid dots, cursive shapes, etc. [3]. At the same time, Arabic calligraphy differs from Chinese calligraphy (brush calligraphy) by seeking balance in letterings and a variety of scales, spacious characters, and density of ink in informal writings.

Some common concepts are often confused for calligraphy. The first concept is hand lettering. Calligraphy means the art of beautiful writing, and it implicates the art of illustrating letters [4]. The difference between calligraphy and hand-lettering involves tools and techniques. Dip pens, brush pens, ruling pens, suede-tip pens are key tools of calligraphy that people do not use in normal handwriting [5]. Another perplexing concept is alphabet, which entails a set of letters in an affixed order ranging from A to $\mathrm{Z}$. The alphabets are letters or symbols to represent basic language or speech, and they can be decorated by the art of calligraphy in many ways [6]. Calligraphy borrows from the alphabet to create a more beautiful letter [2]. Calligraphy is also different from scripture, which involves sacred and religious writings. Again, the word script means a document with letterings while calligraphy makes the decoration in lettering mandatory. Manuscript is also different from calligraphy in the way it involves being contained in a book, document, or music that is hand-written rather than printed or typed [4]. Finally, calligraphy differs from typography in terms of digitizing letters and characters. Calligraphy has wide variation while typography and its mechanical components reflect limitation with decorative and expressive qualities. Many use these terms interchangeably; however, they differ tremendously.

Because Arabic calligraphy is an appealing form of art that is based on its abstractionism and ornamentation - alongside other traditional functions of the symbolic character of mysticism - it has continually evolved to become a tool of communication across cultures. Nowadays, Arabic calligraphy has become the dominant component of art in Saudi Arabia as well as the Muslim world. Arabic inscriptions still adorn the interiors and exteriors of public and private spaces; they are not only confined to art galleries walls [7]. Due to the significant transformations of the global art scene and to the rapid change of Saudi culture, many Saudi artists adapted Western techniques and relied heavily on Western styles to get globally recognized. On the other hand, other artists sounded alarms against unnecessary hybridity and against the idea of losing cultural uniqueness. Therefore, many contemporary Saudi artists - such as Nasser al-Salem - profoundly rely on Arabic calligraphy to assert their Islamic identity and cultural heritage.

\section{ARABIC CALLIGRAPHY IN TRADITIONAL ISLAMIC ARTS}

Since the rise of Islamic arts, Arabic calligraphy has been illustrated in architecture, miniatures, and decorative arts, either in the form of benedictory phrases or religious dedications. In fact, the first documented form of Arabic script emerged around $500 \mathrm{BC}$ in Yemen, and it was called Musnad, which was a development of the Nabatean alphabet [8]. Arabic calligraphy as art dates back to the 7th century Kufa Iraq during the Abbasid era (750-1258 CE) [8]. Kufic script was developed to find a suitable method of documenting the Holy Quran. This was the first time Arabic calligraphy (Khatt) became an artistic discipline of Islamic handwriting [2]. Calligraphy, then became the venerated visual art form through which Quranic scholars expressed themselves and their surroundings [9]. 
Some art history scholars believe that the art of Arabic calligraphy originated as a way to escape the commonly known prohibition of figural representation to avoid paganism and idol worship [9]. Thus, calligraphy came to be the most suitable alternative for not representing living beings in Islamic art [10]. In short, because of the Islamic proscriptions put forth by conservative Muslim scholars who were against figurative imagery, calligraphy was the perfect visual substitute to create art.

The development of Arabic calligraphy was not linear, but instead, there was a wide variety of scripts among different Islamic cultures that rose and fell in popularity. As the Islamic culture spread, so did the Arabic calligraphy with different regions developing customized styles. At the beginning, the Kufic script was the first and foremost celebrated style, and it did not include dots (Nuqat), as they appear in Arabic alphabet today. The dots were added at a later stage by Abu al-Aswad al-Du'ali (688 CE), and then, al-Khalil Ibn Ahmed al-Farahidi (786 CE) developed the diacritical marks (Tashkeel) that indicate the vowels of the letters [8]. Later, the art of calligraphy gradually developed, where various styles were adapted, and more intricate detail was added. There were no rules of how the script was to be used; consequently, the script varied from one region to another, including the rigid forms to decoration [11]. From the 14th century onward, regions such as China and Turkey began to create their own style of calligraphy. Diwani and Riq'a scripts were developed by the Ottomans during the 16th century [12]. Alternatively, the Maghrebi scripts, which were borrowed from the Kufic scripts, were established in North Africa [12]. Other Arabic calligraphy scripts include Sini of China, Tailiq and Thuluth of Persia, and Nasta'liq of South East Asia [13]. All of these scripts are evidence of the omnipresence of Arabic calligraphy during the golden ages of Islamic art.

Kufic and Naskh are the two primary forms of Arabic calligraphy. Kufic script was the earliest form of Arabic Calligraphy, which greatly emphasized linear, rigid, and angular strokes of consonants. The angular variations such as foliated Kufic (curling leaf shapes), floriated Kufic (flower shapes) were seen later. Naskh script on the other hand, is used for informal purposes. Its cursive was well defined and coexisted with the scripts of the Kufic. It was first established in the 10th century and was represented in various styles, and later on, it became the principal foundation of the modern Arabic print [14]. The decorative Arabesque motifs, which accompanied Arabic calligraphy, supported calligraphy to reach the status of spirituality. Quality and emphasis on aesthetics are elements that have continuously been applied by Islamic artists. Recurring patterns of Arabesque in traditional Islamic arts were always combined with geometrical and botanical designs; texts and messages, thus appear to be well hidden by these overlapping designs [15].

The art of calligraphy flourished the most during the Ottoman Empire due to the sultans' vast interest in the language related to the Quran; thus, being a calligrapher was at the time considered to be the most highly regarded and most honored profession [12]. Calligraphy in Islamic art has influenced both linguistic and aesthetic channels and calligraphic writing was considered to be image-texts, which combines images and words with meaningful relations. Aside from religious symbolism, calligraphy writing used to express graphic and spatial qualities too. Hence, Islamic miniatures, which are the painted images that accompanied the written text, were considered an important art form, as demonstrated in Persian, Mughul, and Ottoman miniatures [16]. Today, there are more than 1000 Arabic calligraphy-style fonts and are available digitally [17]. This art form has evolved with time and contemporary artists have introduced flexibility in the conservatism of the Islamic calligraphy. 


\section{MODERNITY AND ARABIC CALLIGRAPHY}

Despite being closely associated with the Quran, Arabic calligraphy was not only a reflection of the centrality of written Islamic texts, but it was also one of the imaginative ways of expressing views and ideas that go beyond the conventional way of pen and paper. Arabic calligraphy continued to be embraced as an exceptional form of Islamic art, and it formed a basis for modern Islamic arts.

By the second half of the 20th century, a new art movement, the Calligraphic School of Art (al-Madrasa al-Huruffiyyah), emerged to encompass Western art techniques and local events [18]. One of the main factors for this new artistic change was that many Arab/Muslim artists had training in the West (Europe and North America) [19]. Consequently, these artists aimed to develop a new style to celebrate modernity (in technique and style) while at the same time, preserving their traditional legacy (in content and perspective). Modern calligraphers utilized celebrated Western art techniques such as Impressionism and Cubism.

Another factor was the writings of Clive Bell (1881-1964) and his theory of the Significant Form, which was published in his book Art in 1914 [20]. He argued, “...there is a particular kind of emotion provoked by works of visual art...the aesthetic emotion" and this emotion can be provoked "by every kind of visual art", so when "lines and colors combined in a particular way, certain forms and relations of forms, stir our aesthetic emotion" [20]. Based on these concepts, modern Arab/Muslim artists found a new way to execute such aesthetics by subtracting the Arabic letter from its form and meaning to represent Arabic letters/words as an autonomous form and as a structural element. The new calligraphic movement differed in the way in which it focused on calligraphic painting (Tasweer Khatti) and calligraphic sculpture (Naht Khatti) rather than the classical calligraphic inscription (al-Khatt al-Arabi) [21]. In this context, modern artists have reduced the sacred scripts to be more representative of symbols or spaces. In other words, they emphasized abstraction by focusing on the conceptuality of the Arabic letter (a significant form) as a decorative element in the composition.

Western modernism has influenced artists to reduce these texts to just strokes or a few lines, a thought that continues to dominate in the present-day. The first one to perform such transformation was the Iraqi artist Madiha Omar (1908-2005) in her exhibition in Washington D.C. in 1949 [21]. For her, the Arabic letter contained a distinct significance; thus, her style combined naturalism and abstraction (Semi-abstraction) [21]. Another famous modern artist was Wajih Nahle (1932-2017) from Lebanon. He was inspired by Persian miniatures, so his works contained calligraphic figures - constructed by human or animal shapes [21]. This new calligraphic movement gained popularity during the 1980s, when Arab/Muslim artists discovered that abstracted alphabet can be a new means to demonstrate their Islamic legacy while at the same time, convoying to the Western art scene.

As mentioned earlier, figural representation was not encouraged, especially among conservative Muslim scholars. However, since it was not entirely banned, especially with recent revisions of religious scriptures, many modern artists heavily relied on figuration to reach a wider crowd, and to break various religious stereotypes while sustaining Islamic identity [22]. For instance, Reza Abedini (b. 1967), an Iranian artist, incorporates images and texts in his work to develop a mystical well-balanced composition. He intertwines Arabic calligraphy with decorative ornamentation and figural representation to convey hidden messages about contemporary issues in his society [15]. Unlike traditional calligraphers, modern artists do not consider the meaning of the Arabic letter/word, but they simply settle with delivering its aesthetic nature.

The development of print media has helped modern calligraphers to redevelop a harmonious connection with the public such as in the works of Ahmed Sabri (painter) (1889- 
1955), and al-Hussain Fawzy (graphic artist) (1905-1995) [23]. On a different level, the modern art movement is often criticized for its rigidity to reform and lack of adaptability to different concepts. Some conventional artists/calligraphers wish not to shift from the characteristic Islamic artform, and they desire to create art only with traditional methods and techniques. That was the key challenge for Arab/Muslim calligraphers by the end of the 20th century. The traditional calligraphic style was never an independent composition, but it was used as a decorative pattern or geometrical arrangement. Modern artists on the other hand, sought more freedom to get out of these strict instructions of art.

\section{ARABIC CALLIGRAPHY IN CONTEMPORARY SAUDI ART}

By the end of the 20th century, many Islamic countries gained their independence and went through intellectual and sociopolitical re-construction, all of which affected the development and creation of art. The prominence of Arabic calligraphy in traditional Islamic arts has influenced its survival even in modern-day Muslim societies. Although elegant Arabic texts continue to play a central role in expressing the Islamic faith, many contemporary Arab artists - namely Saudis - have added a twist to the traditional form of art. Calligraphic art is no longer viewed as a way of conveying clear messages, but rather, it became conceptual configurations [15].

According to Wijdan Ali (b. 1939), the increased influence of Western aesthetics and techniques caused "a loss of cultural identity which created a schizophrenic sense of guilt within the modern Islamic artist: his education and training became totally Western while his beliefs and convictions remained conventional" [24]. This paradox triggered contemporary Arab/Muslim artists to search for an identity that combines their cultural heritage and contemporaneousness. Moreover, such artists constructed their artistic style to assert their individuality to supersede others while maintain originality. They managed to do so by relying on Arabic calligraphy. Unlike modern calligraphers in the 1980 s, many contemporary Islamic artists did not pay much attention to the conceptuality of the letter/word, and they simply endorsed delivering the Western techniques. In this context, contemporary artists infused calligraphic design with expressionist abstraction styles, geometric configurations, and highly charged the works with symbolism. Additionally, what differentiates contemporary artists from their antecedents is their reliance on utilizing current media and techniques. In short, in contemporary Islamic art, Arabic calligraphy mainly combines cultural identity and the language of geometry. The fluidity of the decorative styles helps to create a symmetric and implied organization of design and each iteration redefines the organization for a complete composition.

With the rise of abstraction by the end of the 20th century, some contemporary Arab calligraphers utilized stencil techniques and executed works of graffiti. Through this medium, artists write, paint, or even scribble their messages on walls to comment on modern-day issues. For instance, the Tunisian artist el-Seed (b. 1981), centered his practice on Arabic calligraphy to spread his opinions on certain stereotypes through combining graffiti art and calligraphy, or Calli-graffiti [2]. In 2007, the Dutch artist Niels S. Meulman (b. 1967) introduced the term Calli-graffiti to represent the new fusion of graffiti and the traditional Arabic calligraphic forms of art [25].

Furthermore, modern technology has also played a significant role in changing some of the aspects of Arabic calligraphic art, whereby artists can use technology to enhance their creativity and imagination. Technology has influenced calligraphic art to take on many forms and various inspired styles and techniques. For example, the design prototype projects called the Interactive Calligraphy Exploration (ICE), offers a calligraphic exploration by employing Islamic style symmetry, maintenance, transformation, integration, breaking, etc. [6]. Finally, 
innovation in typography and other printing technology has introduced communication with monumental letter carving, type-face design, two-dimensional graphics using Arabic calligraphy [26].

\section{CRITICAL READING OF NASSER AL-SALEM'S ARTWORKS}

Calligraphy is the handwritten version of typography and the former has higher decorative and expressive qualities. Moreover, legibility is the secondary factor in calligraphy. For example, lettering in paintings and ornamental letterings often emphasize impression, beauty, and decoration rather than clarity; even though the concept of beauty is constantly changing. To understand contemporary calligraphic art in detail, three distinct artworks done by the Saudi artist Nasser al-Salem (b. 1984) are critically analyzed below.

It could be argued that al-Salem is one of the very few contemporary Saudi artists who chose the Arabic letter as his primary approach. While it may seem that al-Salem's contemporary works are similar to traditional Islamic arts, they tremendously differ in concept, medium, and style. Due to the limited space, this study focuses only on three of his well-known calligraphic works. Al-Salem has always been interested in the conceptuality of the Arabic alphabet and its compositional configuration; therefore, his reliance on Arabic script continues to affirm his Saudi cultural heritage and Islamic Identity.

Nasser al-Salem was born in Makkah, KSA [18]. He studied in the Holy Mosque, and achieved an Ijaza certificate, which is the highest form of Islamic calligraphic art. He then earned a bachelor's degree of architecture, which he believes to be a major that is "a close relative of calligraphy" [18], [27]. Predominantly in his works, the Arabic letter/word is the main point of departure; he states, "calligraphy has its own magic; it's captivating" [27]. After a trip to Art Dubai in 2009, al-Salem was exposed to the concept and style of contemporary Western art: "it changed my world view... it was a different world from what I've ever known" [27]. Accordingly, his focus was shifted to re-invent traditional Islamic calligraphic art through creating non-conventional and mixed-media works.

al-Salem is passionate about the Arabic alphabet in Islamic configurations. Some could consider his art devotional due to his reliance on Quranic scriptures. Moreover, al-Nasser's large reliance on Arabic calligraphy was to answer the long-held questions of merging the traditional (Islamic artistic lineage) with contemporaneity (styles and concepts) without affecting Islamic/Saudi identity. Furthermore, depending on abstracting the Arabic alphabet was to convey a deeper meaning beyond the written letter/word. His practice is largely inspired by his personal memories living in Makkah and having personal experience with pilgrims in Hajj season, all of which deeply rooted his cultural identity to negotiate individuality and universalism.

\subsection{Guide us upon the straight path, 2013}

This work (Fig. 1), is a 15 seconds video monitored on a medical screen and accompanied with printed ECG (Electrocardiogram) paper that has the stylized (to some extent deems unreadable) Arabic inscription "guide us upon the straight path", which is an excerpt from

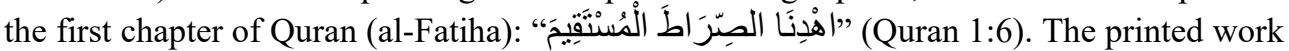
(ECG paper) has a light pink background and it is showing a heartbeat line in bold black color. This installation is accompanied with $100 \times 100 \mathrm{~cm}$ hand-painted image titled Kul (means everything). The artist skillfully uses a bamboo pen to make the calligraphy, which entails a schematized Arabic form of calligraphy. The calligraphy has a tripartite approach to writing where the artist focuses on words, medium, and style. He employs the use of ink on paper, which is aesthetic, resulting in an exciting and exclusive artwork at the end. 

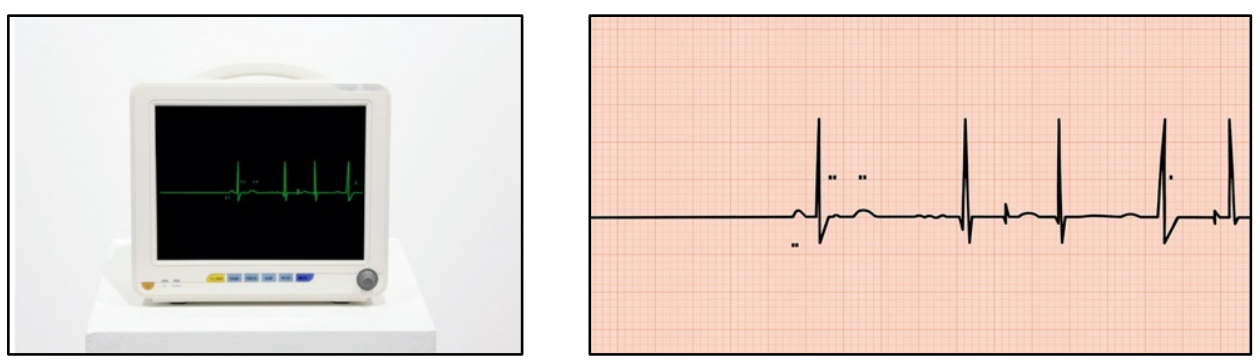

Figure 1: Nasser al-Salem, Guide Us Upon the Straight Path, still from video installation, 2013.

In this artwork, al-Salem utilized a heart monitoring screen and an ECG paper to demonstrate both "an animated [and static] Arabic text stylized as the peaks and troughs of a pulsating heart rate" [18]. This work is a representation of real departure from traditional calligraphy, where it intentionally references the readings of a heartbeat monitor, and also addresses the constituent proportionality of the script [28]. Moreover, the work represents an unbroken and continuous line (without beginning or end) to signify Allah's almighty guidance and omnipresence. For that reason, al-Salem once declared, "[ $\mathrm{t}] \mathrm{o}$ know that God is always around us is a comforting feeling" [27].

Choosing one of the famous verses of Quran was not arbitrary. The inscribed sentence is read by Muslims in their prayers and five times a day. It indicates a request to Allah to guide mortals on the straight path, in which the term "straight path" refers to the path to paradise. In this context, Prophet Muhammed's saying: "the hearts of all human beings are between two fingers of the Merciful as if they are one heart" is significant in which this path demands constant faith in Allah [29]. In the printed ECG paper, there are some scattered dots on both sides of the heartbeat line. In medical terms, scattered dots are defined as fluctuations which can cause harm to the normal heart rate. Thus, the image indicates that faith and good deeds may help people remain on the "straight path". In other words, the straight (good) path is shown by the bold line, while the scattered dots (evil) are the temptations, wrong deeds, sickness that can deviate the person from the right and intended path [19]. Considering contemporary Islamic calligraphic features, the composition is done on a flat surface and the line follows a certain order. Secondly, the emphasis is on two contrasted colors (light and dark) to express abstraction and emphasis on critical life choices [30]. The changes in the line (or sins) are a key feature of contemporary art which is reflected here by the dots. They can also mean the inner self-duality that makes it difficult to stay on the straight path. Finally, the color relationship expresses the inevitability to combine absolutism and abstraction. Therefore, the image covers both Western and Islamic art features which is becoming the celebrated art trend within contemporary Saudi art.

\subsection{Indeed all things we created with predestination, 2014}

In this work of art (Fig. 2), al-Salem omits the letters from the Arabic calligraphy, and only leaving the dots (in black), diacritical marks (in black), and letter scaling-dots and lines (in blue and pencil grey), all of which deem the work incomprehensible. Another popular verse

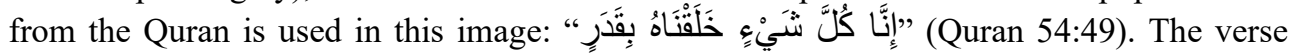
confirms that peoples' lives are not accidental; everything is advantageously planned by Allah Almighty. Concerning color, the artist reduced his palette to two dominant colors: 
black and dark blue on white background, while he is keen to ensure that all critical details of the art are laid out accordingly.

By omitting the Arabic letters, the artist seeks to highlight the details to comprehensively convey the message seemingly to his Arabic-speaking audience. While relying on traditional Arabic calligraphic technique of using natural ink on paper, his way of inscribing the letters is anything but traditional [28]. With regards to its features and style of articulation, calligraphic forms here are quite different from Guide Us upon the Straight Path. Unlike the previous work, which is characterized with simplicity, the work in discussion has an entirely different purpose.

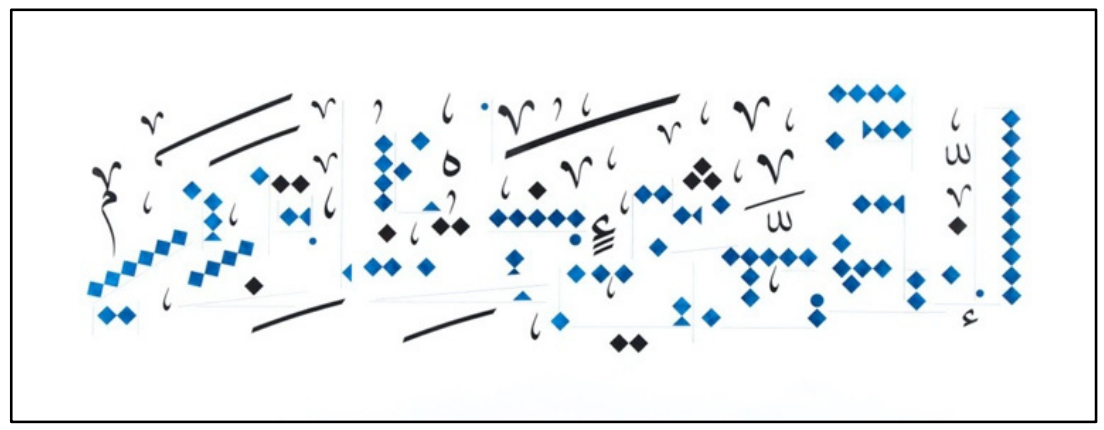

Figure 2: Nasser al-Salem, Indeed All Things We Created with Predestination, 2014.

Everything (animate, inanimate, spiritual) created in this world depends on a well-made supreme plan and is linked by time, place, action, proportion, measure, design, arrangement as well as consequence. Basically, the Almighty plan is done by a predestined fate and on a deeper level, it means that everything happens as the outcome of Allah's will and the Almighty has total control over everything [31]. It is Allah's definitive wisdom that controls and changes everything required. In this context, it is significant that Arabic calligraphy put emphasis on space and proportion as well as geometric shapes which are completely reflected in this artwork. Thus, the calligraphic features here also are predestined according to the verse, and the artist here is granted the intentional freedom. However, the image shows the dynamic relationship between forms and colors, which is a dominating trend in abstract art today [23]. Furthermore, the background is white or opaque, but the drawing pattern lacks changes or accidents. The color relationship expresses rigidity or disassociation, which seems receptive to the autonomy of the supreme power. In this context, it is no wonder al-Salem proclaimed once, "calligraphy has a peculiar energy" [27]. Even though the plan is hidden (letters), life is deemed meticulously balanced and well-predestined. In short, people do not need to observe the foreseen plan of life/destiny to believe that Allah's advantageous and well-determined plan.

\subsection{They will be seen competing in constructing lofty buildings, 2014}

The image (Fig. 3) covers two views of the monotonous concrete sculpture: frontal and top view. This artwork is different from the other two in the way it entails a sculptural execution that employs Islamic texts. Unlike the previous works, this piece involves a critique that is attributed to the Prophet Muhammed (Hadith). Here, the artist describes the extravagant competition, which seems to indicate that intense competition in construction is one of the 
major signs that the Judgment Day is close [22]. The artist incorporates an excerpt from the Prophet: "يَتَطَاَولُونَ فِي الْبنْنَيَانِ" that could be read in the top-view image (right). Its design features are also different from the other two pieces, where it is more complex and has detailed information that requires a more thorough analysis for one to understand fully.

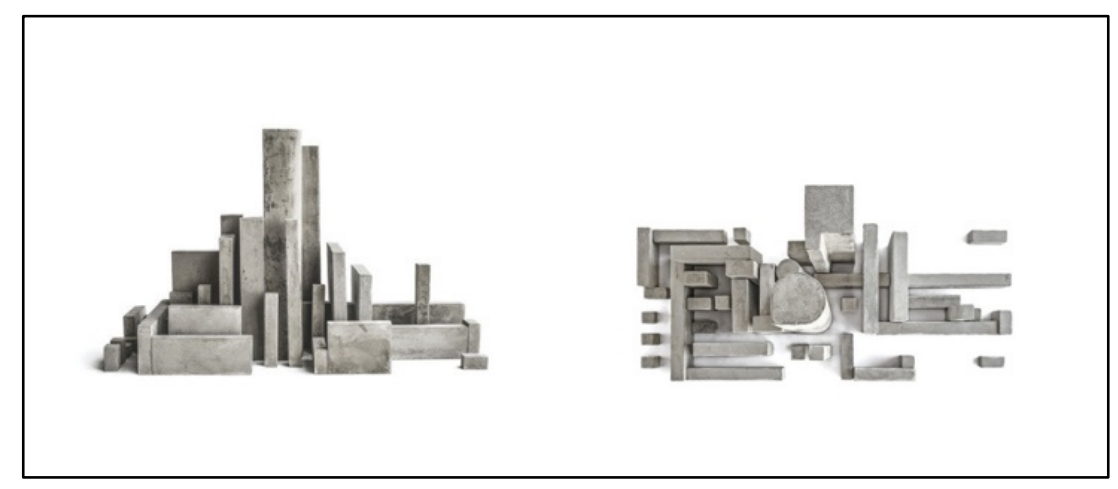

Figure 3: Nasser al-Salem, they will be seen competing in constructing lofty buildings, 2014.

Basically, al-Salem here challenges the boundaries of the traditional Islamic art of Arabic calligraphy by re-contextualizing it in unconventional mixed media forms through minimalist and architectural arrangement. In this work, the artist utilizes a concrete (a relevant architectural medium to proclaim his message) sculptural artwork to criticize the recent construction and building boom in Saudi Arabia, especially after the discovery of oil in the thirties. The position of the excerpt is significant as top view indicates that people should dissociate themselves from the materialistic issues to understand the heavenly influence on them. The color relationship expresses gloom and inevitability with white background and grey artwork. Furthermore, the geometric arrangement reflects the Arabic calligraphic features (Squared Kufic style) such as the importance of space, symmetry, and abstraction. The artwork seems inspired by the optical effect of the traditional calligraphic art and the top view confirms the same [23]. Again, the static feature of the artwork indicates that people are ignorant of heavenly influences when fighting for selfish materialistic needs.

All of these three works of art heavily borrow from the Islamic scriptures, where the artist potentially asserts his religious affiliation and cultural heritage. The analysis of the three images confirms that digital design may offer a position of multidimensional possibilities, but the Arabic calligraphy has not shifted from its root. It has added plurality to the visual and textual conventions. Therefore, technological development has increased the integration of Arabic lettering, images, decoration of words as well as symbolic icons. Moreover, the artist has increased diversity of the layout options by reducing the limitation of texts and decorative styles. Digital designers do not challenge the traditional technical features, but they try to create a collaborative environment to acquire new trends. However, considering a specific set of traditional assumptions, the digital format, to some extent, challenges uniform spacing, sequential arrangement, and static flow. In the historical trajectory, contemporary metaphors and visual strategies work as a shock, but they open new opportunities and scopes for the symbolic conditions [32]. For example, contemporary Saudi artists such Nasser al-Salem, are prone to use dynamic color relationships, accidental changes, and 
symmetry-breaking themes while focusing on instrumental and technological exchanges and representations. Contemporary Arabic calligraphy also combines printed and pre-printed communications reflecting both the visual and aesthetic elements of inscription. Indeed, digital networks preserve and extend distributive elements in the pictographic space. For example, logos, computer icons have multidimensional and extended meaning where repeatability is a flexible feature with idiosyncratic components [30]. Accordingly, contemporary Saudi art has increased clarity of traditional calligraphy and is helping the Muslim community to make calligraphy a powerful icon of cultural identity.

\section{CONCLUSION}

People always appreciate art despite the nature of the language used. The same applies to artworks that have Arabic calligraphy. Spectators appreciate the craftsmanship, uniqueness and adroitness of artists, where one can tell about a great art piece without even understanding the language. In other words, there is no need to comprehend the written inscription to understand messages each artwork represents. The deconstruction and reinvention of Arabic calligraphy by contemporary Arab/Muslim artists is aimed at making art more accessible to the audiences [33]. The incomprehension of the words does not only apply to Arabic-based works, but instead, to all types of art across the globe. Viewers, in most cases, are mesmerized by how artists articulate the work without minding whether they understand the language. When non-Arabic speakers view such artworks, they can better understand the culture and traditions involved that are manifested by the art piece. This could be true as al-Salem proclaims, "although you could say my work is very much inspired by my religion, I by no means have a specific audience, and hope that my messages have a spiritual or historical significance for everyone" [34]. Therefore, this means that wording or the use of a different language cannot affect the appreciation of any artwork. In short, art is a universal language that is appreciated by everyone despite their age, language, culture, race, or origin.

Considering the waves of immigration in the USA, the Arab-American community is a diverse group and includes different religious backgrounds due to the inclusion of third and fourth generation individuals. The multiculturalism, adoption of Western culture, and the increased anti-Arab stereotyping in the global population have a direct effect on non-Arabic audience when viewing Arabic-based artworks. It is also observed that the global non-Muslim population easily connects terrorism with Arab/Islamic communities, which is an obvious reason why people cannot see Arabic artworks beyond religious rigidity. However, typography and fusion of Western-Eastern styles (hybrid intersections) are currently gaining positive feedback. What contemporary Saudi artists are trying to do is make people look beyond the religious issues and make the global community more flexible to receive the abstraction and beauty of Arabic calligraphy. Reliance solely on Arabic calligraphy (contemporary Saudi artists in general, and Nasser al-Salem in particular) was to celebrate the Arabic language and cultural heritage. Many Saudi artists did that to challenge negative stereotypes of Arab/Muslims, and to demystify the misrepresentation of Saudis, especially after $9 / 11$.

In conclusion, Arabic Calligraphy is a form of art which represents the Islamic culture and the teachings of the Quran. Traditionally, it involves the use of decorative handwriting by the use of a pen or a brush. Arabic Calligraphy has evolved over the years, where contemporary calligraphic artists borrowed most of their skills. This art is arguably seen to be originated from the common-known prohibition of representing living beings in Islam. Accordingly, it was used for spiritual purposes, and for portraying present-day events. In this study, Nasser al-Salem, a contemporary Saudi artist, was chosen due to his reliance on Arabic letters/words as a primary point of departure. Three of his main works of arts were critically analyzed: 
Guide Us upon the Straight Path, 2013; Indeed All Things We Created with Predestination, 2014; and They Will Be Seen Competing in Constructing Lofty Buildings, 2014.

Nasser al-Salem's works of art are innovative, dynamic, and challenging to modern-day stereotypes. He is generally looking for multiple perspectives and styles to express rapid changes in Saudi society. With the advent of modern technology and new artistic media, contemporary Islamic art could not be expressed through traditional approaches, which dominated the Islamic/Arab art scene for centuries. Therefore, al-Salem is working not only to bring about a new understanding of Saudi art, but also to express himself on a worldwide platform through modernizing Arabic calligraphy. He embodies a new understanding of what contemporary Saudi art should be: the emphasis on conversations between past and present styles, traditional and modern techniques, and Eastern and Western understandings. Considering all of these concepts, Nasser al-Salem is contributing to art diplomacy and to improve our understanding of contemporary Islamic art, and to enable a new stimulating dialogue between cultures.

\section{ACKNOWLEDGEMENTS}

I would like to express my special thanks and gratitude to my mom and my family, who supported me all along. I could not have done it without your support.

\section{REFERENCES}

[1] Isqineeha, They will be seen competing in constructing lofty buildings. www.isqineeha.tumblr.com/post/103837534039/they-will-be-seen-competing-inconstructing-lofty. Accessed on: 25 Feb. 2020.

[2] Issa, R. \& Cestar, J. (eds), Arabicity: Contemporary Arab Art, Saqi Books: UK, pp. $17-19,2019$.

[3] Turgut, Ö., Calligraphic forms in contemporary typographic design. Procedia-Social and Behavioral Sciences, 122, pp. 40-45, 2014.

[4] Lettering Daily, The difference between hand lettering and calligraphy? www.lettering-daily.com/difference-between-hand-lettering-and-calligraphy. Accessed on: 25 Feb. 2020.

[5] Sunni, Guide us to the straight path. www.sunnionline.us/english/2013/09/18/3009/. Accessed on: 25 Feb. 2020.

[6] Choudhrey, S., Pigment to pixel: An investigation into digital Islamic art in the UK. $\mathrm{PhD}$ dissertation, University of Kent, 2018.

[7] The Embassy of the Kingdom of Saudi Arabia, About Saudi Arabia, culture and arts. www.saudiembassy.net/culture-art. Accessed on: 22 Feb. 2020.

[8] Clarke, M., Neo-calligraphy: Religious authority and media technology in contemporary Shiite Islam. Comparative Studies in Society and History, 52(2), pp. 351-383, 2010.

[9] Silka, P., Where is Arabic calligraphy in contemporary Art? www.widewalls.ch/ arabic-calligraphy-contemporary-art. Accessed on: 23 Feb. 2020.

[10] Sida, A., Arabic calligraphy in contemporary Egyptian murals with an essay on Arab tradition and art. PhD dissertation, The Ohio State University, 1965.

[11] Alessio, J., Understanding the difference between type and lettering. www.smashingmagazine.com/2013/01/understanding-difference-between-type-andlettering. Accessed on: 23 Feb. 2020.

[12] Gazi, A., The interest of the Ottoman sultans of Arabic calligraphy and Islamic arts. Eurasian Journal of Researches in Social and Economics, 6(5), pp. 191-210, 2019. 
[13] Meulman, N., What is Calligraffiti? www.calligraffiti.nl/what-is-calligraffiti.html. Accessed on: 23 Feb. 2020.

[14] Clayton, E., A short history of calligraphy and typography. www.bl.uk/history-ofwriting/articles/a-short-history-of-calligraphy-and-typography. Accessed on: 25 Feb. 2020.

[15] Ludescher, T., From nostalgia to critique: An overview of Arab American literature. Melus, 31(4), pp. 93-114, 2006.

[16] Moustapha, H. \& Krishnamurti, R., Arabic calligraphy: A computational exploration. 3rd International Conference on Mathematics and Design, pp. 294-306, 2001.

[17] Hammond, R., Why calligraphy is important? www.9mousai.com/why-calligraphy-isimportant. Accessed on: 25 Feb. 2020.

[18] Ali, W., Modern Islamic Art: Development and Continuity, University Press of Florida: Gainsville, pp. 151-184, 1997.

[19] Alshahrani, A., Arabic script and the rise of Arabic calligraphy. PhD dissertation, New Castle University, 2008.

[20] Osborn, J.R., The type of calligraphy: Writing, print, and technologies of the Arabic alphabet. PhD dissertation, UC San Diego, 2008.

[21] Yaman, A., Here is a look at the history of Arabic calligraphy www.stepfeed.com/heres-a-look-at-the-history-of-arabic-calligraphy-9958. Accessed on: 22 Feb. 2020.

[22] al-Dhalaan, B., Divine decree and predestination. www.inspiredmindsmag.com/ divine-decree-and-predestination. Accessed on: 25 Feb. 2020.

[23] Victoria \& Albert Museum, Calligraphy in Islamic art. www.vam.ac.uk/content/ articles/c/calligraphy-in-islamic-art. Accessed on: 25 Feb. 2020.

[24] Ali, W. (ed.), Modern Islamic Art: Development and Continuity, Scorpoin Publishing: UK, pp. xii-25, 1989.

[25] Essa, A. \& Othman, A., Studies in Islamic Civilizations: The Muslim Contribution to the Renaissance, International Institute of Islamic Thought: Virginia, p. 19, 2012.

[26] Mohamed, N. \& Youssef, K., Utilization of Arabic calligraphy to promote the Arabic Identity in packaging designs. Arts and Design Studies, 19, pp. 35-49, 2014.

[27] Ayad, M., Blackburn, V. \& Habib, R. (eds), Contemporary Kingdom: The Saudi Art Scene Now, Canvas central: UAE, pp. 139-143, 2014.

[28] McLaughlin, T., Clive Bell's aesthetic: Tradition and significant form. The Journal of Aesthetics and Art Criticism, 35(4), pp. 433-443, 1977.

[29] Sharp, D., The Arab city: Architecture and representation. Arab Studies Journal, 25(2), pp. 202-206, 2017.

[30] Khajavi, M., Arabic Script in Motion: A Theory of Temporal Text-based Art, Palgrave Macmillan: Switzerland, pp. 29-31, 2019.

[31] Smash Magazine, Arabic calligraphy: Having a closer look. www.smashingmagazine.com/2014/03/taking-a-closer-look-at-arabic-calligraphy. Accessed on: 22 Feb. 2020.

[32] Messick, B., The Calligraphic State: Textual Domination and History in a Muslim Society, University of California Press: California, pp. 116-119, 1996.

[33] Edge of Arabia, Artists, Nasser al-Salem. www.edgeofarabia.com/artists/nasser-alsalem. Accessed on: 27 Feb. 2020.

[34] Teparic, M., Figural representation in the Arabic calligraphy. Epiphany Journal of Disciplinary Studies, 6(2), pp. 146-160, 2014. 